\title{
To Determine the Effects of Labor Induction on Maternal and Fetal Outcome in Postterm Pregnancies (41 Weeks Plus)
}

\author{
Milad M. M. Gahwagi, Farag Benali, Nagat M. Bettamer, Asma Soliman Zubi \\ Department of Obstetrics \& Gynecology, Faculty of Medicine, Benghazi University, Benghazi, Libya \\ Email:mila@gahwagi.ly
}

How to cite this paper: Gahwagi, M.M.M., Benali, F., Bettamer, N.M. and Zubi, A.S. (2017) To Determine the Effects of Labor Induction on Maternal and Fetal Outcome in Postterm Pregnancies (41 Weeks Plus). International Journal of Clinical Medicine, 8, 98-110.

https://doi.org/10.4236/ijcm.2017.82009

Received: November 21, 2016

Accepted: February 20, 2017

Published: February 23, 2017

Copyright $\odot 2017$ by authors and Scientific Research Publishing Inc. This work is licensed under the Creative Commons Attribution International License (CC BY 4.0).

http://creativecommons.org/licenses/by/4.0/

(c) (i) Open Access

\begin{abstract}
Background: Pregnancies progressing postterm are associated with a higher perinatal morbidity and mortality rates than those delivered at term. In a United Kingdom study, the rate of stillbirth increased from 0.35 in 1000 live births in pregnancies of 37 weeks to 2.12 in 1000 live births in pregnancies of 43 weeks gestation. Morbidities associated with postterm births include an increased risk of fetal distress, intrauterine growth restriction, dysfunctional labor, shoulder dystocia, obstetric trauma (relative risk 1.09 - 1.68) and an increase in perinatal complications, such as aspiration of meconium and asphyxia, peripheral nerve injury, greenstick bone fractures, pneumonia and septicemia (adjusted odds ratio 1.4 - 2.0). Antenatal surveillance and induction of labor may decrease the risks of an adverse outcome. In a recent review of term and postterm pregnancies in Norway, we found that there were adverse outcomes associated with both postterm pregnancy and induction of labor independently. On comparison of the two, a randomized controlled trial showed no difference in their neonatal outcome, but demonstrated a reduction in the cesarean delivery rate when labor was induced at 41 weeks. Aim of the Work: The aim of this study was to determine the effect of labor induction on maternal and fetal outcome in postterm pregnancies. Subjects and Methods: This study was carried out on 150 pregnant women who had completed 41 weeks of gestation between Jun. 1, 2012 up to Dec. 31, 2012 at Department of Obstetrics \& Gynecology, Faculty of Medicine, Benghazi University, and were scheduled for induction of labor after cardiotocography (CTG) and ultrasonography (USS) have been done and Bishop's score assessed, to determine the effects of labor induction on maternal and fetal outcome in postterm pregnancies (41 weeks plus). Results: Regarding the relationship between a history of $(\mathrm{H} / \mathrm{O})$ postdatism and fetal distress, it was found that there was no significant relationship between them. There was a significant relationship between a history of macrosomia and fetal distress. There was a
\end{abstract}


significant relationship between instrumental delivery and fetal distress. The majority of the fetal distress had an indication for Caesarean section (CS) (fetal distress (FD) and fetal distress meconium (FDM) more than those without fetal distress. All fetuses that had APGAR scores of 8 were distressed. There was a significant relationship between the APGAR score at 10 minutes with fetal distress. All fetuses that had meconium aspiration had fetal distress. There was a significant increase in the amount of oxytocin in unit in distressed cases than the non-distressed ones. The total duration of induction was also significantly increased in stressed fetuses than the non-stressed ones. There was a significant increase in the weight of distressed fetuses than the non-distressed. Conclusions: In conclusion, there was no difference in the neonatal outcome or mode of delivery for postterm pregnancies managed either by immediate induction of labor or expectantly with serial antenatal surveillance. The outcomes were generally good, and neonatal morbidity, cesarean section, and operative vaginal delivery rates were low. If pregnancy is uncomplicated and continued surveillance is possible, women's own wishes may guide the decision to induce or monitor a pregnancy beyond 41 weeks.

\section{Keywords}

Postterm Pregnancy, Mortality Rate

\section{Introduction}

There is an increased risk of fetal and neonatal morbidity and mortality in postterm pregnancies [1] as well as an increased maternal morbidity [2]. Stillbirths occurring at and beyond term (37 - 42 weeks gestation) are a major public health problem contributing more to perinatal mortality than either deaths from complications of prematurity or the sudden infant death syndrome [3]. Induction of labour at term is used to prevent this high fetal mortality from postterm pregnancies; however, both clinicians and patients alike are concerned about the its risks, which include uterine hyper-stimulation, failed induction and increased Caesarean section rates. Postterm pregnancies are also associated with increased costs which arise from antenatal monitoring of the foetus and the cost of inducing labour [4], in addition to being a source of significant anxiety for the pregnant woman [5]. Optimization of these conflicting pressures still poses a clinical challenge.

A normal term pregnancy is between 37 and 42 weeks of gestation with a progressive increase in the perinatal morbidity and mortality rates during this period. In clinical practice, it is important, yet very difficult to define an "ideal" time when the benefits of a medical intervention (induction of labor) outweigh the benefits of the natural evolution of pregnancy. Both preterm (defined as delivery before 37 completed weeks of gestation) and postterm (delivery at or beyond 41 week of gestation) births are associated with increased neonatal morbidity and mortality. Postterm pregnancy constantly remains a difficult and 
controversial problem in modern obstetrics. Postterm pregnancy, by definition, refers to a pregnancy that has extended to or beyond 41 weeks of gestation (294 days, or estimated date of delivery (EDD) +14 days), and it complicates $10 \%$ of all gestations [6] [7]. Accurate dating of the pregnancy is critical to the diagnosis [6]. The most frequent cause of an apparently postterm pregnancy is an error in dating. When postterm pregnancy truly exists, the cause is usually unknown [6]. Postterm antenatal fetal surveillance traditionally begins at 42 completed weeks of gestation; however, recent data have shown that a significant percentage of cases of perinatal asphyxia occur between 40 and 42 weeks of gestation. Some studies [8] [9] mentioned that the pregnancy risks start increasing from gestational week 41. In this paper, we have reviewed the literature data about the diagnosis of postterm pregnancy, prenatal indicators, and maternal fetal outcomes of prolonged pregnancy, and the timing to start the antepartum fetal tests.

The aim of the study was to determine the effects of labor induction on maternal and fetal outcome in postterm pregnancies (41 weeks plus) of patients attending the obstetrics department of Aljamhoria Hospital, Benghazi and to evaluate the outcome of mother and fetus.

\section{Subjects and Methods}

\subsection{Subjects}

A total of 150 women who reached 41 weeks + gestation between June 1, 2012 and Dec 31, 2012 at the Department of Obstetrics \& Gynecology, Faculty of Medicine, Benghazi university and who were scheduled for induction of labor after a normal CTG and USS and a favourable Bishop's score were included in this prospective observational study.

Caesarean delivery rates were calculated for those who underwent induction.

\subsection{Exclusion Criteria}

Women with any medical or obstetric risk factors were excluded, e.g. previous CS, women aged more than 35 years, multipara ( $>4$ delivery), multiple pregnancy, any medical disease (hypertension or diabetes) and unreactive CTG or biophysical profile (BPP).

\section{Methods}

Women assigned to both arms of the study had the same baseline assessment: an ultrasound scan (with emphasis on estimated fetal weight and amniotic fluid volume), a cardiotocogram, and a clinical vaginal examination. For women assigned to continued antenatal assessment, induction of labor was arranged if the cardiotocogram recordings were abnormal, the estimated fetal weight was less than 2 standard deviations, or oligohydramnios (amniotic fluid index less than 5 $\mathrm{cm}$ or single deepest pocket less than $2 \mathrm{~cm}$ ) was found. If these investigations are normal, they were reassessed every third day until spontaneous delivery occurred, or until labor was induced on day 300 . 
Women who had a favorable cervix (Bishop score of 6 or more) were induced by amniotomy followed by oxytocin Syntocinon, infusion. Women with an unfavorable cervix (Bishop score less than 6) had cervical priming using misoprostol (prostaglandin $\mathrm{E}_{1} 50 \mathrm{mcg}$ pessary encased in a gelatin capsule) at 6-hour intervals in the posterior fornix. A maximum of four doses were given in a 24-hour period, and cervical priming was continued for a maximum of 2 days. Once the cervix was favorable, amniotomy and oxytocin infusion were used. Women with a uterine scar were induced with $0.5 \mathrm{mg}$ dinoprostone (prostaglandin $\mathrm{E}_{2}$, Minprostin endocervical gel) given intracervically every 12 hours.

Women being induced, or being assessed on admission in labor, had a cardiotocogram. If this was abnormal, or if meconium was seen after rupture of membranes, then a continuous electronic fetal monitoring was recommended. Antenatal, intrapartum, and postnatal data were collected on a single chart that accompanied the patient through this period and was completed by the staff contemporaneously. The charts were designed to allow automatic optical recognition and transmission to a computer database based in the University Clinical Trials Office. The process of data transmission was checked for error by two of the authors (R.H. and E.S.).

\subsection{The Outcome of the Neonate Was Recorded}

Meconium aspiration, Birth asphyxia, neonatal (NN) death, Still birth.

Neonatal morbidity was primarily defined by assessing a series of relevant outcomes. Information about the presence of meconium, birth weight, crownheel length, Apgar scores, umbilical cord $\mathrm{pH}$, and base excess and the need for resuscitation were recorded immediately after delivery. Supplementary medical information was obtained from the routine pediatric examination on the first or second day, and if admitted, from the neonatal intensive care unit (NICU).

Neonatal morbidity was scored by evaluating the degree of deviation from the potential of a perfect outcome for each newborn. We defined a perfect outcome as being an infant with a birth weight of $3.8 \mathrm{~kg}$ and a Ponderal Index of 2.88 (a measure of weight relative to length obtained from 180 healthy newborns with gestational age 287 days or more acting as controls in a study of preeclampsia). Other optimal features for outcome were considered to be 1- and 5-minute Apgar scores of 10, umbilical cord $\mathrm{pH}$ of 7.40 with base excess equal to 0 (zero), and no medical complications or need for treatment. To compare the study groups, we assigned a priori weights to the outcome variables based on clinical judgment and consensus among the researchers. The sum in each neonate constitutes a Neonatal Morbidity score, which increases with increasing morbidity. One Neonatal Morbidity unit corresponds to, for example, the presence of meconium, a one-point decrease in the 5-minute Apgar score, or a $\mathrm{pH}$ decrease of 0.1. We further calculated the Canadian Multicenter postterm Pregnancy neonatal morbidity index developed by Hannah et al. [9], in which morbidity was defined when the upper 2 percentile was exceeded.

Severe perineal lacerations were defined as third and fourth-degree perineal 
lacerations during delivery. Maternal hemorrhage was defined as blood loss more than $500 \mathrm{ml}$ at delivery. Uterine contraction abnormalities were defined as prolonged first stage of labor (less than $1 \mathrm{~cm}$ cervical dilatation per 1.5 hours), prolonged active second stage of labor (longer than 1 hour) and short active second stage of labor (less than 15 minutes). Precipitate labor was defined as a total length of labor less than 3 hours.

\subsection{Ethical Considerations}

- Approval was taken from the ethics committee.

- Each participant was informed about the aim and procedures of the study and consent to participate in the study was obtained.

\section{Results}

This study was carried out on 150 pregnant women who reached more than 41 weeks' gestation between Jun 1, 2012 and Dec 1, 2012 and who were scheduled for induction of labor after a normal CTG and USS and a favourable Bishop's score, to determine the effects of labor induction on maternal and fetal outcome in postterm pregnancies (41 weeks plus).

Table 1 shows the incidence of caesarean section and fetal distress among the studied group, it was found that a caesarean section was done in 17 cases (11.3\%) and fetal distress was found in 16 cases (10.7\%).

Table 2 shows the relationship between nationality and fetal distress. It was found that there was no significant association between nationality and fetal distress $(p>0.05)$.

Table 1. Distribution of the studied patients regarding the caesarean delivery and fetal distress.

\begin{tabular}{ccc}
\hline & Number & Percent \\
\hline Caesarean section & 17 & 11.3 \\
Fetal distress & 16 & 10.7 \\
Normal delivery & 117 & \\
Total study group & 150 & 100.0 \\
\hline
\end{tabular}

Table 2. Nationality in relation to fetal distress.

\begin{tabular}{|c|c|c|c|c|c|}
\hline & & & \multicolumn{2}{|c|}{ Fetal distress } & \multirow[b]{2}{*}{ Total } \\
\hline & & & $\begin{array}{c}\text { No } \\
N=134\end{array}$ & $\begin{array}{c}\text { Yes } \\
\mathrm{N}=16\end{array}$ & \\
\hline \multirow{4}{*}{ Nationality } & \multirow{2}{*}{ Libyan } & No & 127 & 15 & 142 \\
\hline & & $\%$ & $94.8 \%$ & $93.8 \%$ & $94.7 \%$ \\
\hline & \multirow{2}{*}{ Non Libyan } & No & 7 & 1 & 8 \\
\hline & & $\%$ & $5.2 \%$ & $6.3 \%$ & $5.3 \%$ \\
\hline \multicolumn{2}{|c|}{$\mathrm{X}^{2}$} & \multicolumn{4}{|c|}{0.030} \\
\hline \multicolumn{2}{|c|}{$p$} & \multicolumn{3}{|c|}{604} & \\
\hline
\end{tabular}


Table 3 shows the relationship between blood group and fetal distress. It was found that there was a significant relationship between blood group $\mathrm{B}$ and $\mathrm{O}$ $\mathrm{RH}$ - and the incidence of fetal distress $(p<0.05)$.

Table 4 shows the relationship between booking status and fetal distress. It was found that there was no significant relationship between booking status and fetal distress.

Table 5 shows the relationship between $\mathrm{H} / \mathrm{O}$ postdatism and some other variables. It demonstrates that there was no significant relationship between $\mathrm{H} / \mathrm{O}$ of postdatism and fetal distress $(p>0.05)$. All the patients that had H/O macrosomia had fetal distress, showing a significant relationship between the two $(p<$ $0.05)$. The majority of fetal distress cases were from caesarean section delivery, indicating a significant relationship between CS and fetal distress $(p<0.01)$.

Table 3. Blood group and $\mathrm{RH}$ group in relation to fetal distress.

\begin{tabular}{|c|c|c|c|c|c|}
\hline \multicolumn{2}{|c|}{ BL GR RH+ } & \multicolumn{2}{|c|}{ Fetal distress } & \multirow{2}{*}{ Total } & \multirow{2}{*}{$\begin{array}{r}\mathrm{X}^{2} \\
p\end{array}$} \\
\hline & & No & Yes & & \\
\hline \multirow{2}{*}{$\mathrm{A}$} & No & 32 & 3 & 35 & \\
\hline & $\%$ & $23.9 \%$ & $18.8 \%$ & $23.3 \%$ & \\
\hline \multirow{2}{*}{$\mathrm{AB}$} & No & 12 & 2 & 14 & \\
\hline & $\%$ & $9.0 \%$ & $12.5 \%$ & $9.3 \%$ & 1.103 \\
\hline \multirow{2}{*}{ B } & No & 19 & 3 & 22 & 0.894 \\
\hline & $\%$ & $14.2 \%$ & $18.8 \%$ & $14.7 \%$ & \\
\hline \multirow{2}{*}{$\mathrm{O}$} & No & 45 & 4 & 49 & \\
\hline & $\%$ & $33.6 \%$ & $25.0 \%$ & $32.7 \%$ & \\
\hline \multicolumn{6}{|c|}{ BL GR RH- } \\
\hline \multirow{2}{*}{ A } & No & 11 & 0 & 11 & \\
\hline & $\%$ & $8.2 \%$ & $.0 \%$ & $7.3 \%$ & \\
\hline \multirow{2}{*}{$\mathrm{AB}$} & No & 3 & 0 & 3 & \\
\hline & $\%$ & $2.2 \%$ & $.0 \%$ & $2.0 \%$ & 18.670 \\
\hline \multirow{2}{*}{ B } & No & 0 & 2 & 2 & $0.001^{\star}$ \\
\hline & $\%$ & $.0 \%$ & $12.5 \%$ & $1.3 \%$ & \\
\hline \multirow{2}{*}{$\mathrm{O}$} & No & 12 & 2 & 14 & \\
\hline & $\%$ & $9.0 \%$ & $12.5 \%$ & $9.3 \%$ & \\
\hline
\end{tabular}

Table 4. Booking of the pregnancy in relation to fetal distress.

\begin{tabular}{|c|c|c|c|c|c|}
\hline & & & \multicolumn{2}{|c|}{ Fetal distress } & \multirow[b]{2}{*}{ Total } \\
\hline & & & $\begin{array}{c}\text { No } \\
N=133\end{array}$ & $\begin{array}{c}\text { Yes } \\
N=16\end{array}$ & \\
\hline \multirow{4}{*}{ Booked } & \multirow{2}{*}{ No } & No & 1 & 0 & 1 \\
\hline & & $\%$ & $0.7 \%$ & $0.0 \%$ & $0.7 \%$ \\
\hline & \multirow{2}{*}{ Yes } & No & 133 & 16 & 149 \\
\hline & & $\%$ & $99.3 \%$ & $100.0 \%$ & $99.3 \%$ \\
\hline & & \multicolumn{4}{|c|}{0.120} \\
\hline & & \multicolumn{4}{|c|}{0.893} \\
\hline
\end{tabular}


Table 5. Relationship between relevant history and other variables.

\begin{tabular}{|c|c|c|c|c|c|c|}
\hline \multirow{2}{*}{\multicolumn{3}{|c|}{ History of $(\mathrm{H} / \mathrm{O})$ postdatism }} & \multicolumn{2}{|c|}{ Fetal distress } & \multirow{2}{*}{ Total } & \multirow{2}{*}{$\begin{array}{c}\mathrm{X}^{2} \\
p\end{array}$} \\
\hline & & & No & Yes & & \\
\hline \multirow{2}{*}{\multicolumn{2}{|c|}{ No }} & No & 116 & 15 & 131 & \\
\hline & & $\%$ & $86.6 \%$ & $93.8 \%$ & $87.3 \%$ & 667 \\
\hline \multirow{2}{*}{\multicolumn{2}{|c|}{ Yes }} & No & 18 & 1 & 19 & 0.366 \\
\hline & & $\%$ & $13.4 \%$ & $6.3 \%$ & $12.7 \%$ & \\
\hline \multirow{2}{*}{\multicolumn{2}{|c|}{$\mathrm{H} / \mathrm{O}$}} & No & 134 & 14 & 148 & \\
\hline & & $\%$ & $100.0 \%$ & $87.5 \%$ & $98.7 \%$ & 16.76 \\
\hline \multirow[t]{3}{*}{ Macrosomia } & & No & 0 & 2 & 2 & $0.011^{*}$ \\
\hline & Ies & $\%$ & $.0 \%$ & $12.5 \%$ & $1.3 \%$ & \\
\hline & CS & No & 6 & 11 & 17 & \\
\hline \multirow[t]{3}{*}{ MOD CS } & & $\%$ & $4.5 \%$ & $68.8 \%$ & $11.3 \%$ & 58.758 \\
\hline & Normal & No & 128 & 5 & 133 & $0.001^{*}$ \\
\hline & & $\%$ & $95.5 \%$ & $31.3 \%$ & $88.7 \%$ & \\
\hline \multirow{4}{*}{ CS } & \multirow{2}{*}{ Emergency } & No & 4 & 9 & 13 & \\
\hline & & $\%$ & $30.7 \%$ & $69.3 \%$ & $6.7 \%$ & 6.672 \\
\hline & \multirow{2}{*}{ Elective } & No & 2 & 2 & 4 & $0.048^{*}$ \\
\hline & & $\%$ & $50.0 \%$ & $50.0 \%$ & $2.7 \%$ & \\
\hline \multirow{6}{*}{ Indication CS } & \multirow{4}{*}{ Fetal distress } & No & 1 & 0 & 1 & \multirow{6}{*}{$\begin{array}{c}38.34 \\
0.0001^{\star}\end{array}$} \\
\hline & & $\%$ & $0.7 \%$ & $0.0 \%$ & $0.7 \%$ & \\
\hline & & No & 5 & 4 & 9 & \\
\hline & & $\%$ & $3.7 \%$ & $25.0 \%$ & $6.0 \%$ & \\
\hline & \multirow[t]{2}{*}{ Fetal distress \& meconium } & No & 0 & 2 & 2 & \\
\hline & & $\%$ & $0.0 \%$ & $12.5 \%$ & $1.3 \%$ & \\
\hline \multirow{6}{*}{$\begin{array}{l}\text { Apgar score } \\
10 \mathrm{~min}\end{array}$} & \multirow{2}{*}{8.00} & No & 0 & 5 & 5 & \multirow{6}{*}{$\begin{array}{c}45.958 \\
0.0001^{\star}\end{array}$} \\
\hline & & $\%$ & $0.0 \%$ & $31.3 \%$ & $3.3 \%$ & \\
\hline & \multirow{2}{*}{9.00} & No & 70 & 9 & 79 & \\
\hline & & $\%$ & $52.2 \%$ & $56.3 \%$ & $52.7 \%$ & \\
\hline & \multirow{2}{*}{10.00} & No & 64 & 2 & 66 & \\
\hline & & $\%$ & $47.8 \%$ & $12.5 \%$ & $44.0 \%$ & \\
\hline \multirow{4}{*}{ SEX } & \multirow{2}{*}{ Female } & No & 97 & 8 & 105 & \\
\hline & & $\%$ & $72.4 \%$ & $50.0 \%$ & $70.0 \%$ & 3.412 \\
\hline & \multirow{2}{*}{ Male } & No & 37 & 8 & 45 & 0.063 \\
\hline & & $\%$ & $27.6 \%$ & $50.0 \%$ & $30.0 \%$ & \\
\hline
\end{tabular}

The relationship between type of CS and fetal distress found that the emergency CS showed a high percentage of fetal distress, $(p<0.05)$.

The relationship between the indication for CS and fetal distress found that the majority of the fetal distress cases had an indication for CS (FD, and FDM) 
more than the non-fetal distress indication $(p<0.01)$.

It was found that all fetuses that had Apgar scores of 8 were distressed, showing a significant relationship between Apgar score at $10 \mathrm{~min}$ and fetal distress $(p$ $<0.001)$.

There was no significant relationship between fetal distress and sex of the fetus.

There was a significant association between the respiratory distress syndrome and fetal distress $(p<0.01)$.

Table 6 shows the relationship between fetal distress and different risk factors. Regarding duration of hospital stay, it was found that there was a significant increase in hospital stay period in fetal distress cases than the others. Gestational age was found not to have any significant effect on the inncidence of fetal distress. The number of props given did not show any association to fetal distress neither did the duration from start of induction to transfer to labour room.

There was a significant increase in the amount of oxytocin in unit in distressed cases than the non-distressed cases $(p<0.05)$, and the total duration of induction, also showed a significant increase in stressed fetuses than the nonstressed $(p<0.05)$.

The level of haemoglobin $(\mathrm{Hb})$ before and after delivery showed no significant relationship to fetal distress $(p>0.05)$. There was a significant increase in the weight of distressed fetuses than the non-distressed ones $(p<0.01)$.

\section{Discussion}

In our study, it was found that there was a significant relationship between blood group $\mathrm{B}$ and $\mathrm{O} \mathrm{RH}-$ and the incidence of fetal distress.

In agreement with our study, Denomme et al., (2004) showed that there was a significant positive correlation between maternal ABO-mismatched blood and fetal distress [10].

Table 6. Relationship between fetal distress and different risk factors.

\begin{tabular}{ccccc}
\hline & Without fetal distress & With fetal distress & t-test & $p$ \\
\hline $\begin{array}{c}\text { DAY OF STAY } \\
\text { IN HOSPITAL }\end{array}$ & $2.6716 \pm 1.11$ & $3.75 \pm 1.183$ & 13.186 & $0.0001^{*}$ \\
GA (WEEKS) & $42.21 \pm 0.22$ & $42.31 \pm 0.30$ & 0.21 & 0.62 \\
No of Props given & $2.1866 \pm 0.75$ & $2.500 \pm 0.73$ & 2.464 & 0.119 \\
$\begin{array}{c}\text { Duration from start of induction } \\
\text { to transfer to Labor room }\end{array}$ & $2.2162 \pm 0.75$ & $2.4667 \pm 0.63$ & 1.499 & 0.223 \\
$\begin{array}{c}\text { Amount of oxytocin in unit } \\
\text { Total Duration of }\end{array}$ & $9.5224 \pm 5.58$ & $13.2500 \pm 5.56$ & 6.362 & $0.013^{*}$ \\
induction and labor & $2.7090 \pm 1.05$ & $3.6875 \pm 0.83$ & 3.064 & $0.042^{*}$ \\
$\begin{array}{c}\text { Hb level before delivery } \\
\begin{array}{c}\text { Hb level after delivery } \\
\text { WT/gm }\end{array}\end{array}$ & $11.10 \pm 0.50$ & $10.50 \pm 0.44$ & 1.017 & 0.085 \\
& $9.9366 \pm 0.50$ & $9.9250 \pm 0.51$ & 0.008 & 0.931 \\
\hline
\end{tabular}


In our study, it was found that there was no significant relationship between booking status and fetal distress. In disagreement to our study, however, Jaspinder and Kawaljit (2012) demonstrated that a higher incidence of fetal distress was seen in unbooked mothers $(61.12 \%)$ when compared to booked mothers (38.89\%) [11].

A recent study conducted by Khatoon et al. showed that one of the most common reasons for referral among unbooked women was fetal distress, evidenced by meconium stained liquor. The high incidence rate of birth asphyxia due to Fetal Distress prior to birth in unbooked mothers has been reported by various authors in their research works. It reveals that young age and an unbooked status might had withdrawn them from taking antenatal care at an early gestational age or till the development of obstetric complications which had led to the development of antepartum or intrapartum fetal hypoxia and distress [12].

In this study, it was found that there was a significant relationship between H/O macrosomia and CS with fetal distress. Jaspinder and Kawaljit (2012) found that emergency Caesarean section occurred in $79.17 \%$ of mothers with Fetal Distress [11].

In our study, we found that all fetuses that had an Apgar score of 8 were distressed indicating a significant relationship between Apgar score at $10 \mathrm{~min}$ and fetal distress. Mojbian et al. (2013) found that there were statistically significant differences between APGAR score and fetal distress [13].

In our study, there was no significant relationship between fetal distress and sex of the fetus.

In this study, all the fetuses that had meconium aspiration had fetal distress, showing a significant association between the respiratory distress syndrome and fetal distress. There was a significant increase in hospital stay period in fetal distress cases than the others. It was found that there was no significant difference between the two studied groups regarding gestational age.

There was a significant increase in the amount of oxytocin in unit in distressed cases than the non-distressed. The total duration of induction also shows a significant increase in stressed fetuses than the non-stressed.

There was no significant relationship between Hb level and fetal distress. Jaspinder and Kawaljit (2012) showed that anemia was associated with the highest incidence of Fetal Distress (34.73\%). Oligohydraminos, Pregnancy Induced Hypertension and Intrauterine Growth Retardation were responsible for Fetal Distress in $19.45 \%, 18.06 \%$ and $18.06 \%$ of cases, respectively. The various other obstetric conditions implicated in a decreasing order were: Meconium Stained Amniotic Fluid (16.67\%), Preterm Labor with Scar tenderness (16.67\%), Preterm Premature Rupture of Membrane (12.50\%), Postdatism (12.50\%), Placenta Previa (09.73\%), Uteroplacental Insufficiency (06.95\%), True Nuchal Knot (06.95\%), Failed Labour (05.56\%) and Gestational Diabetes mellitus (02.78\%) [11].

In this study, the weight of the baby was directly proportional to the incidence of fetal distress. 
This study shows that policies of immediate induction of labor or serial antenatal monitoring while awaiting spontaneous labor produce no significant differences in the neonatal outcome or mode of delivery of postterm pregnancies. Women who were induced were more likely to have a precipitate labor with a shorter active second stage, although these factors did not alter neonatal outcome.

The study of postterm pregnancies is complicated by the fact that both the normal duration of pregnancy and the best method to define the estimated delivery of pregnancy remain controversial. In Norway, the normal duration of pregnancy is defined as 282 days, in line with several studies examining the mean and mode of pregnancy duration. Similarly, ultrasonography has been shown to be the method of choice for defining the estimated date of delivery (where equipment and trained personnel are available) and is found to reduce the number of pregnancies defined as being postterm [14] [15]. In Norway, pregnancies are routinely dated by ultrasonography at 18 weeks and we defined the point for investigating the postmature pregnancy as being one complete week beyond the normal duration of pregnancy, i.e., 289 days.

Several studies have demonstrated that the risks of stillbirth and perinatal mortality increase beyond 41 weeks of gestation [16] [17]. Despite this, the absolute mortality rate remains quite low, and it would take at least 500 inductions at 41 weeks to prevent one neonatal death [5]. Consequently, the maternal and fetal morbidity related to induction of labor are potentially important issues and were the subject of investigation here. This study was not designed to examine differences in mortality. Indeed, there were no fetal deaths in the study, and the only neonatal death related to birth asphyxia was secondary to a true knot in the cord. This death would probably not have been avoided by induction a few days earlier [17].

In the process of designing this study we reviewed the methodology used by other investigators to define neonatal morbidity. We found most scoring systems unsuitable for a quantitative comparison of the study groups [18], among other things because they focus on premature infants, NICU admission, and mortality. The Neonatal Morbidity score was based on suboptimal outcomes which have been described as being associated with postterm delivery. This scoring system was tested in two pilot studies before the randomized trial. To quantify neonatal outcome, we constructed the "perfect infant" and defined multiple criteria to assess the deviation from this. The weight ascribed to various criteria could be debated, but the fundamental design of the trial-including randomization and a priori definitions-ensures a valid group comparison. The morbidity index used by Hannah et al. [19] was also calculated, but the index is difficult to interpret clinically and provided no further information on neonatal morbidity.

Mothers who had Preterm Premature Rupture of Membrane (PPROM) further experienced Fetal heart rate abnormalities (12.05\%). Moberg et al. [20] suggested an increased incidence of fetal distress in patients with PPROM due to the 
loss of protection of umbilical cord that amniotic fluid normally provides. Postdated pregnancy ( $>40$ weeks gestation) led to non-reassuring fetal heart rate $(12.50 \%)$ as concluded by James et al. [21] in their study. Fetal distress was found in mothers with an abnormal location of placenta (placenta previa) (9.73\%) in our study [22]. Fetuses with a true nuchal cord (06.95\%) experienced in-utero hypoxia and distress. Begum et al. [23] concluded that a true nuchal cord is a sign of fetal distress in their study but did not consider it as an indication for operative delivery. The study done in 2010 by Geidam et al. [24] found no significant differences between cases and controls of fetal distress in terms of age, parity, booking status, presence of obstetric conditions, duration of operation and birth weight of babies.

Fetal distress was diagnosed by fetal heart rate (FHR) and presence of meconium. However, an accurate method for establishment of fetal distress is to perform a fetal scalp blood $\mathrm{pH}$ estimation which is considered the gold standard for assessment of fetal wellbeing but is not done in our setup. Cardiotocography monitoring is known to overestimate fetal distress [13]. This shows that the method of screening used for making the diagnosis of fetal distress has its own limitations [25]; however, the first response when fetal distress is detected or suspected is that of intrauterine resuscitation which will improve the condition of the fetus and may help to avoid an unnecessary intervention. An alteration of maternal position, Hydration, Oxygen, Intravenous hypertonic dextrose, Amnioinfusion, Tocolysis, etc. [17] are some of the measures which can be used for resuscitation. However, in some cases of fetal distress, an immediate operative delivery may be the only option to ensure a healthy neonate.

Various factors like young age, lack of awareness regarding provision of antenatal care, lack of health education, negligence, financial constraints, environmental \& cultural prejudices, male involvement in maternal health care, poor nutritional status of young women (anemia), lack of transport facility, and absence of patient counseling prior to planning of mode of delivery might be responsible for the late booking status with decompensated obstetrics condition resulting in fetal hypoxia, asphyxia and distress [25].

\section{References}

[1] Olesen, A.W., Basso, O. and Olsen, J. (2003) Risk of Recurrence of Prolonged Pregnancy. British Medical Journal, 326, 476. https://doi.org/10.1136/bmj.326.7387.476

[2] Caughey, A.B., Stotland, N.E., Washington, A.E. and Escobar, G.J. (2007) Maternal Obstetric Complications of Pregnancy Are Associated with Increasing Gestational Age at Term. American Journal of Obstetrics \& Gynecology, 196, 155.e1-155.e6. https://doi.org/10.1016/j.ajog.2006.08.040

[3] Cotzias, C.S., Paterson-Brown, S. and Fisk, N.M. (1999) Prospective Risk of Unexplained Stillbirth in Singleton Pregnancies at Term: Population Based Analysis. British Medical Journal, 319, 287-288. https://doi.org/10.1136/bmj.319.7205.287

[4] Allen, V.M., O’Connell, C.M., Farrell, S.A. and Baskett, T.F. (2005) Economic Implications of Method of Delivery. American Journal of Obstetrics \& Gynecology, 193, 192-197. https://doi.org/10.1016/j.ajog.2004.10.635 
[5] ACOG (American College of Obstetricians and Gynecologists) (1998) Management of Postterm Pregnancy. ACOG Practice Bulletin No. 6 (1997). International Journal of Gynecology \& Obstetrics, 60, 86-91. https://doi.org/10.1016/S0020-7292(98)90448-9

[6] ACOG (2004) Management of Postterm Pregnancy. ACOG Practice Bulletin No. 55. ACOG, Washington DC.

[7] Norwitz, E.R., Snegovskikh, V.V. and Caughey, A.B. (2007) Prolonged Pregnancy: When Should We Intervene? Clinical Obstetrics and Gynecology, 50, 547-557. https://doi.org/10.1097/GRF.0b013e31804c9b11

[8] Bochner, C.J., Williams III, J., Castro, L., Medearis, A., Hobel, C.J. and Wade, M. (1988) The Efficacy of Starting Postterm Antenatal Testing at 41 Weeks as Compared with 42 Weeks of Gestational Age. American Journal of Obstetrics \& Gynecology, 159, 550-554. https://doi.org/10.1016/S0002-9378(88)80005-X

[9] Lisa, H., Shanthi, S. and Baskaran, T. (2007) Influence of Parity on Fetal Mortality in Prolonged Pregnancy. European Journal of Obstetrics \& Gynecology and Reproductive Biology, 132, 167-170. https://doi.org/10.1016/j.ejogrb.2006.07.010

[10] Denomme, G.A., Ryan, G., Seaward, P.G., Kelly, E.N. and Fernandes, B.J. (2004) Maternal ABO-Mismatched Blood for Intrauterine Transfusion of Severe Hemolytic Disease of the Newborn Due to Anti-Rh17. Transfusion, 44, 1357-1360. https://doi.org/10.1111/j.1537-2995.2004.04082.x

[11] Jaspinder, K. and Kawaljit, K. (2012) Conditions behind Fetal Distress. Annals of Biological Research, 3, 4845-4851.

[12] Khatoon, A., Hasny, S.F., Irshad, S. and Ansari, J. (2011) Fetal Distress. Pakistan Journal of Surgery, 27, 304-308.

[13] Mojibian, M., Mostafavi, M. and Karimi, M. (2013) Evaluation of the Relationship between Fetal Distress and $\mathrm{Ph}$ of Umbilical Cord Artery of Neonates. Middle-East Journal of Scientific Research, 13, 20-24.

[14] Gardosi, J. and Geirsson, R.T. (1998) Routine Ultrasound Is the Method of Choice for Dating Pregnancy. BJOG, 105, 933-936. https://doi.org/10.1111/j.1471-0528.1998.tb10253.x

[15] Gardosi, J., Vanner, T. and Francis, A. (1997) Gestational Age and Induction of Labour for Prolonged Pregnancy. BJOG, 104, 792-797. https://doi.org/10.1111/j.1471-0528.1997.tb12022.x

[16] Divon, M.Y., Haglund, B., Nisell, H., Otterblad, P.O. and Westgren, M. (1998) Fetal and Neonatal Mortality in the Postterm Pregnancy: The Impact of Gestational Age and Fetal Growth Restriction. American Journal of Obstetrics \& Gynecology, 178, 726-731. https://doi.org/10.1016/S0002-9378(98)70482-X

[17] Smith, G.C. (2001) Life-Table Analysis of the Risk of Perinatal Death at Term and Post Term in Singleton Pregnancies. American Journal of Obstetrics \& Gynecology, 184, 489-496. https://doi.org/10.1067/mob.2001.109735

[18] Fleisher, B.E., Murthy, L., Lee, S., Constantinou, J.C., Benitz, W.E. and Stevenson, D.K. (1997) Neonatal Severity of Illness Scoring Systems: A Comparison. Clinical Pediatrics, 36, 223-227. https://doi.org/10.1177/000992289703600407

[19] Hannah, M.E. (1993) Postterm Pregnancy: Should All Women Have Labour Induced? A Review of the Literature. Fetal and Maternal Medicine Review, 5, 3-17. https://doi.org/10.1017/S0965539500000681

[20] Moberg, L.J., Garite, T.J. and Freeman, R.K. (1984) Fetal Heart Rate Patterns and Fetal Distress in Patients with Preterm Premature Rupture of Membranes. Obstetrics \& Gynecology, 64, 60-64. 
[21] James, C., George, S.S., Gaunekar, N. and Seshadri, L. (2001) Management of Prolonged Pregnancy: A Randomized Trial of Induction of Labour and Antepartum Foetal Monitoring. National Medical Journal of India, 14, 270-273.

[22] Hsu, Y.C., Lin, C.H., Chang, F.M. and Yeh, T.F. (1998) Neonatal Outcome of Preterm Infants Born to Mothers with Placenta Previa. Clinical Neonatology, 5, 1.

[23] Begum, A.A., Sultana, H., Hasan, R. and Ahmed, M. (2011) A Clinical Study of Fetal Outcome in Cases of Nuchal Cord. JAFMC Bangladesh, 7, 25-27.

[24] Geidam, A., Bako, B., Ibrahim, S. and Ashir, M. (2010) Early Neonatal Outcome of Babies Delivered by Cesarean Section Because of Clinical Diagnosis of Fetal Distress. The Internet Journal of Gynaecology \& Obstetrics, 12, 2.

[25] Thaker, S.B. and Stroup, D.F. (2001) Continuous Electronic Heart Rate Monitoring for Fetal Assessment during Labor. Cochrane Database of Systematic Reviews, 1, CD000063.

Submit or recommend next manuscript to SCIRP and we will provide best service for you:

Accepting pre-submission inquiries through Email, Facebook, LinkedIn, Twitter, etc. A wide selection of journals (inclusive of 9 subjects, more than 200 journals)

Providing 24-hour high-quality service

User-friendly online submission system

Fair and swift peer-review system

Efficient typesetting and proofreading procedure

Display of the result of downloads and visits, as well as the number of cited articles

Maximum dissemination of your research work

Submit your manuscript at: http://papersubmission.scirp.org/

Or contact ijcm@scirp.org 